\title{
First observations from a CCD all-sky spectrograph at Barentsburg (Spitsbergen)
}

\author{
S. A. Chernouss, O. M. Sharovarova, Yu. V. Fedorenko, A. V. Roldugin, and L. S. Yevlashin \\ Polar Geophysical Institute of the Kola Science Centre RAS, Apatity, Murmansk region, 184200 Russia \\ Received: 23 January 2007 - Revised: 30 July 2007 - Accepted: 23 January 2008 - Published: 28 May 2008
}

\begin{abstract}
A digital CCD all-sky spectrograph was made by the Polar Geophysical Institute (PGI) to support IPY activity in auroral research. The device was tested at the Barentsburg observatory of PGI during the winter season of 20052006. The spectrograph is based on a cooled CCD and a transmission grating. The main features of this spectrograph are: a wide field of view $\left(\sim 180^{\circ}\right)$, a wide spectral range $(380-740 \mathrm{~nm})$, a spectral resolution of $0.6 \mathrm{~nm}$, a background level of about $100 \mathrm{R}$ at 1-min exposure time. Several thousand spectra of nightglow and aurora were recorded during the observation season. It was possible to register both the strong auroral emissions, as well as weak ones. Spectra of aurora, including nitrogen and oxygen molecular and atomic emissions, as well as $\mathrm{OH}$ emissions of the nightglow are shown. A comparison has been conducted of auroral spectra obtained by the film all-sky spectral camera C-180-S at Spitsbergen during IGY, with spectra obtained at Barentsburg during the last winter season. The relationship between the red $(630.0 \mathrm{~nm})$ and green $(557.7 \mathrm{~nm})$ auroral emissions shows that the green emission is dominant near the minimum of the solar cycle activity (2005-2006). The opposite situation is observed during 1958-1959, with a maximum solar cycle activity.
\end{abstract}

Keywords. Atmospheric composition and structure (Airglow and aurora; Instruments and techniques) - Magnetospheric physics (Polar cap phenomena)

\section{Introduction}

The spectral characteristics of auroral luminosity inside polar caps differ from that measured in the main auroral ovals. The main difference is that in the polar caps the intensity of integral luminosity and of some auroras is significantly lower

Correspondence to: S. A. Chernouss

(chernouss@pgi.kolasc.net.ru) than in the auroral oval. Besides, a large region of red luminosity in the emissions 630.0-636.4 nm (Yevlashin, 1961; Sandford, 1961; Sandholt et al., 1993, 2002) appears near the northern boundary of the oval.

The Polar Geophysical Institute continues the tradition of spectral observations in Spitsbergen, which were started by the Russian expedition in 1899 (Chernouss et al., 2005) and continued in 1957-1959 during the International Geophysical Year (Yevlashin, 1961). A meridian scanning photometer and low light level all-sky TV (SIT) camera are in operation at the Barentsburg observatory of PGI. The aim of this paper is to present a new CCD all-sky spectral camera S-180. In addition, a preliminary estimation of the characteristics of auroral luminosity in the emissions $557.7 \mathrm{~nm}$ and $630.0 \mathrm{~nm}$ are presented. The data are observed in the polar cap of the Northern Hemisphere at Barentsburg $\left(\Phi \sim 74.4^{\circ} \mathrm{N}, \Lambda \sim 130.7^{\circ} \mathrm{E}\right.$ ) during the minimum of solar activity (2005-2006) using the new spectrograph. A comparison of these spectra with the ones which had been registered in the years of very high solar activity (1958-1959) in Pyramida $\left(\Phi \sim 74.7^{\circ} \mathrm{N}, \Lambda \sim 130.8^{\circ} \mathrm{E}\right)$ is presented.

\section{Equipment and methods}

A Digital CCD all-sky spectrograph S-180 was made by the Polar Geophysical Institute (PGI) to support forthcoming International Polar Year (IPY) activity in auroral research. The device was tested at the Barentsburg observatory during the winter season of 2005-2006. The spectrograph is based on cooled CCD and a transmission grating. The main features of this spectrograph are: a wide field of view $\left(\sim 180^{\circ}\right)$, a wide spectral range $(380-740 \mathrm{~nm})$, a spectral resolution of $0.6 \mathrm{~nm}$, background level at 1-min time exposure is about $100 \mathrm{R}$ (see Table 1). The general view, the optical diagram of the S-180 and samples of auroral and nightglow spectra are shown in Figs. 1-4. The performance of the spectrograph's parameters

Published by Copernicus Publications on behalf of the European Geosciences Union. 
Table 1. Instrumental parameters of the All-Sky CCD Image Spectrograph S-180.

\begin{tabular}{ll}
\hline Field-of-view (degrees) & $180 \times 0.75$ \\
Angular resolution (degrees) & 0.25 \\
Spectral range (nm) & $380-740,420-870$ \\
Spectral resolution (nm) & 0.6 \\
background level for $557.7 \mathrm{~nm}(\mathrm{R})$ & 100 \\
Dynamic range & 65536 \\
Sampling rate (frame/min) & 1 \\
Temperature range & $-45 \ldots+30^{\circ} \mathrm{C}$ \\
Power & $90-264 \mathrm{~V} / 47-63 \mathrm{~Hz}$ \\
\hline
\end{tabular}

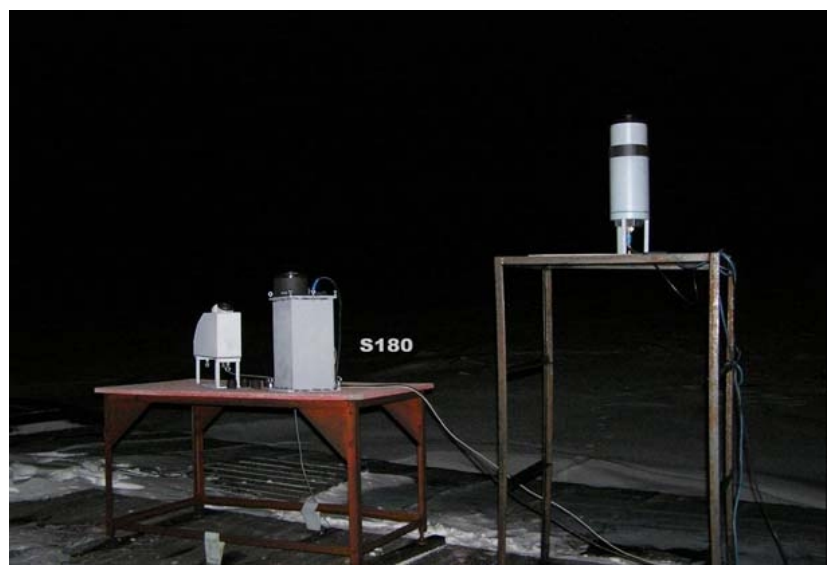

Fig. 1. The auroral CCD spectral camera S-180 at PGI Barentsburg observatory.

is compared with similar all-sky spectral instruments made by other researchers: film all-sky spectral camera C-180-S (Lebedinsky, 1961); all-sky spectrograph ASG (Koizumi et al., 2004). Figure 5a, b shows photos of the C-180-S spectral film camera. Figure 5c, d demonstrates examples of auroral spectrum obtained by the C-180-S camera during the 19581959 years in Pyramida (Spitsbergen). Obviously, the new device permits us to obtain auroral spectra with higher time resolution (about two orders). Table 2 gives us a comparison between spectrographs.

\section{Data and results}

The red-to-green ratio of auroral oxygen line intensity is a good indicator of the energy spectrum of the precipitating electrons. The auroral oxygen emission $\mathrm{O}[\mathrm{I}] 630.0 \mathrm{~nm}$ is excited by particles with energy of few hundred ev and the emission $\mathrm{O}[\mathrm{I}] 557.7 \mathrm{~nm}$ by particles with an average energy 1-10 kev (Rees, 1989; Vallance Jones, 1974; Sandholt et al., 2002). The aurora with dominating intensity of the red emission at the top part of auroral forms was classified as "type A red" aurora (International Auroral Atlas, 1963; Chamberlain,

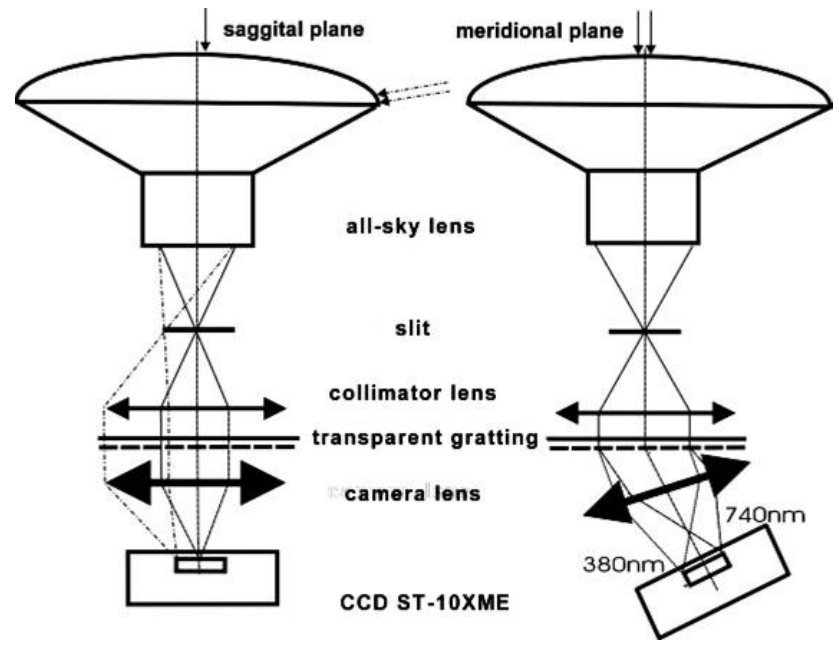

Fig. 2. Optical diagram of the auroral CCD spectral camera S-180.

Table 2. Spectrograph's parameters comparison.

\begin{tabular}{lccc}
\hline Type & C-180-S & ASG & S180 \\
\hline Year & 1957 & 1999 & 2005 \\
field of view (deg.) & 180 & 180 & 180 \\
spectral range (nm) & $380-680$ & $447-766$ & $380-740$ \\
& & & $420-870$ \\
spectral resolution (nm) & 1.4 & 2.0 & 0.6 \\
angular resolution (deg.) & 0.57 & 0.72 & 0.25 \\
background level for & & & \\
$557.7 \mathrm{~nm}(\mathrm{R})$ & 300 & 50 & 100 \\
\hline
\end{tabular}

1961). Type A red aurora are usual for the cleft region precipitations and they could be a signature of penetration of the solar wind soft particles into the magnetosphere and upper atmosphere. Spitsbergen is one of the best places for measurements of aurora of this kind. A comparison of an occurrence rate of auroral events with dominant red or green emission during both high and low solar activity can give us valuable information on the primary source of type A red aurora. We have a good opportunity to perform this analysis based on auroral spectra measurements at Spitsbergen in the 1958-1959 winter season (years of high solar activity) and in the 2005-2006 season (years of low solar activity). The original data of 1958-1959 (Pyramida) were taken from the World Data Centre - WDC-B2 in PGI and from the expedition of PGI to Spitsbergen in 2005-2006 (Barentsburg). The film camera C-180-S data of 1958-1959 from Pyramida were analyzed by standard visual comparative photometry method (Yevlashin, 1961). Digital data of the S-180 CCD camera from Barentsburg were processed and analyzed by the methods derived (Roldugin et al., 2006) to compare the old film spectral data from Pyramida with the new digital data from Barentsburg. A standard time exposure of the film camera 


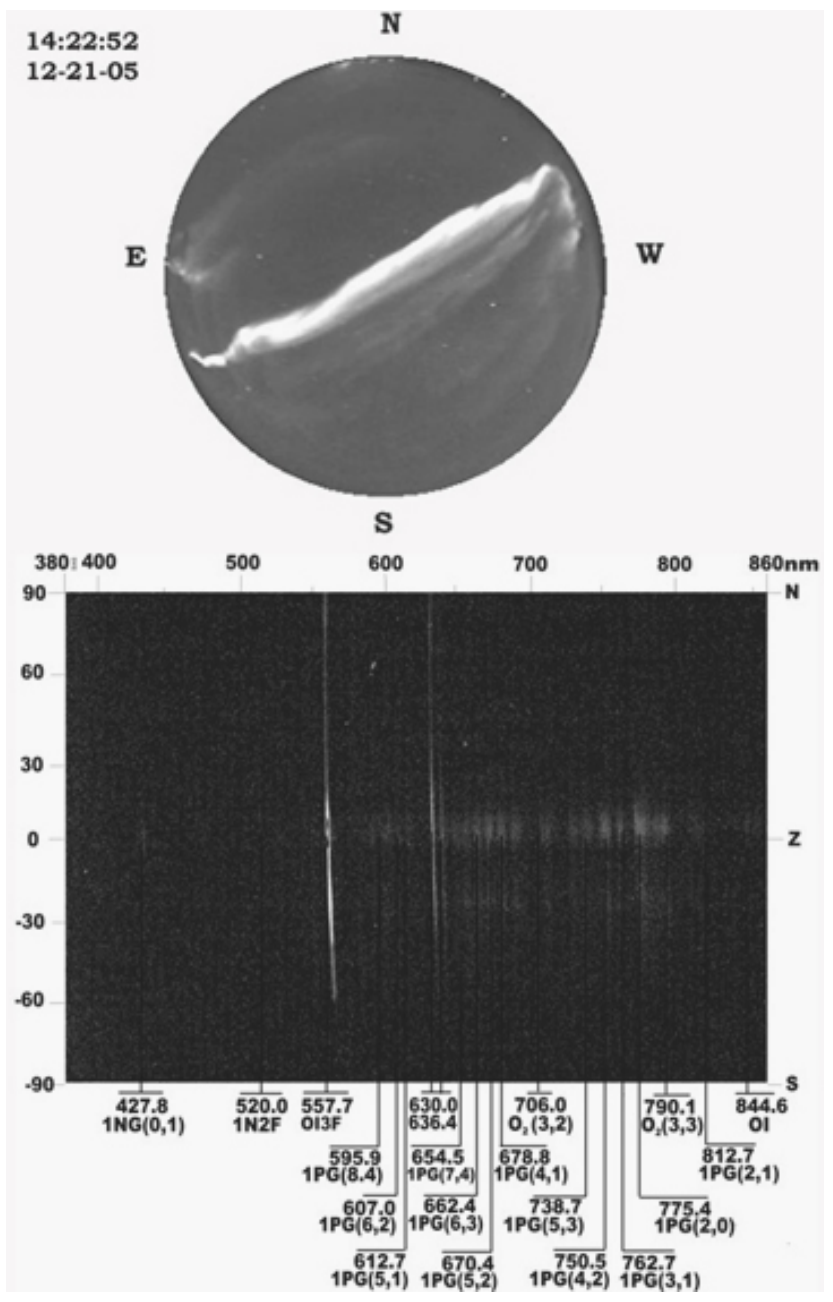

Fig. 3. Example of an auroral spectrum registered by CCD spectral camera with 1-min exposure (lower panel) and auroral image registered by the TV (SIT) camera in Barentsburg (upper panel).

was 10 min. The integration time of the CCD camera data was also $10 \mathrm{~min}$. The period of observations in Pyramida lasted from November 1958 to February 1959. The monthly averaged number of sunspots was 172 in this time interval. The total number of samples suitable for analysis was 1703 . The period of observations in Barentsburg lasted from December 2005 to January 2006. The monthly averaged number of the sunspots was 28 . The total number of the integrated spectra was 905 . The ratio I 630.0/I 557.7 was calculated from the data of both stations. The criterion of choosing between "the red" and "the green" aurora was the ratio 1.5. This rough criterion is based on the spectral response of the human eye and it is connected with a visual detection level of auroral red color and comparison of this level with instrumental spectral observations (Sandford, 1961; Hanna and Anger, 1971). If the intensity of the red line exceeds 1.5 times the green line intensity in an auroral pattern, this pattern was identified as "the red" aurora. "The green" aurora

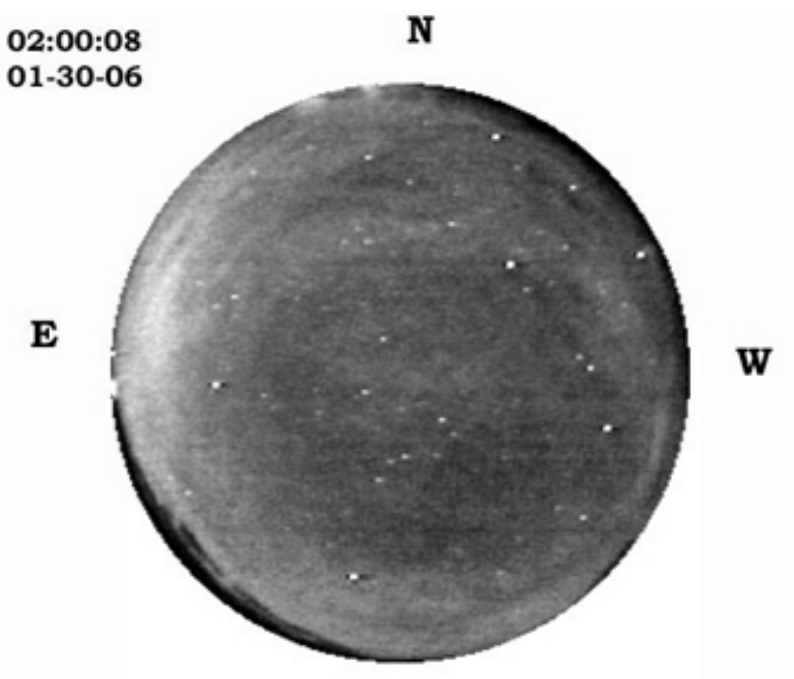

$\mathbf{s}$

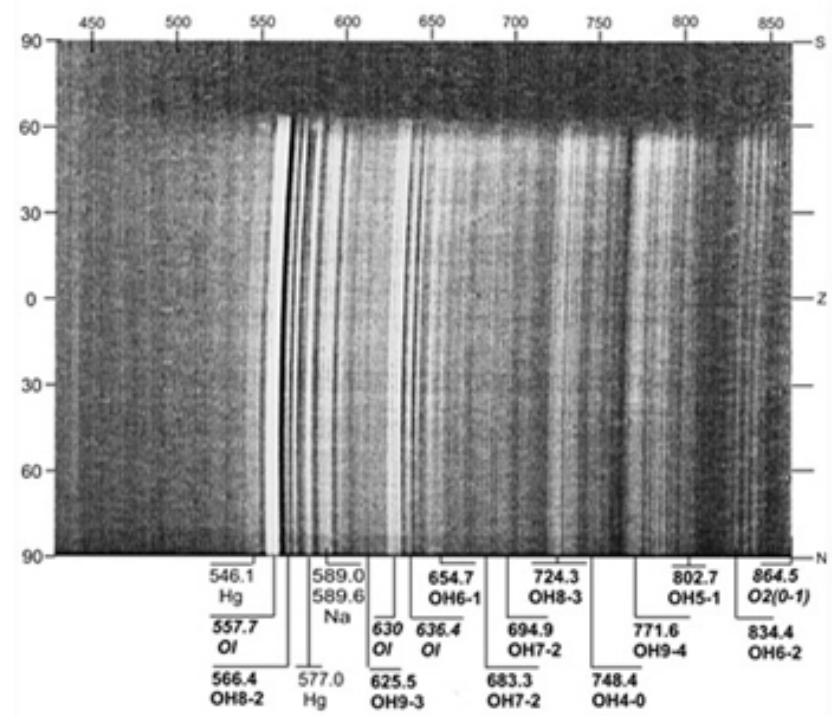

Fig. 4. Example of the nightglow spectrum registered by CCD spectral camera with integration time one hour (low panel) and nightglow image registered by the TV (SIT) camera in Barentsburg during time without aurora (upper panel).

was indicated in the opposite case, if this ratio intensity of the red line did not exceed 1.5. A comparative evaluation of the intensities ratio in 1958-1959 showed that the intensity of the emission $630.0 \mathrm{~nm}$ exceeded 1.5 in 719 spectra, i.e. $42.2 \%$ of the analyzed spectra (Fig. 6). It was found that the number of spectra, in which the intensity of the red emission exceeded the intensity of the green emission by factor of 1.5 and more was only $2.4 \%$ in the 2005-2006 data (Fig. 6). 


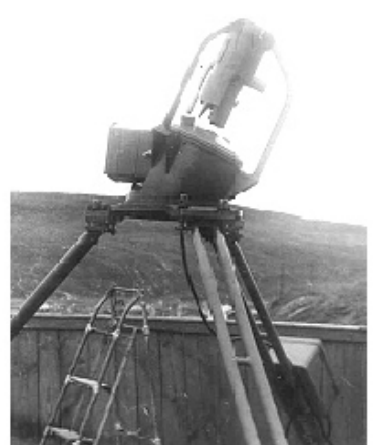

C-180-S camera

a

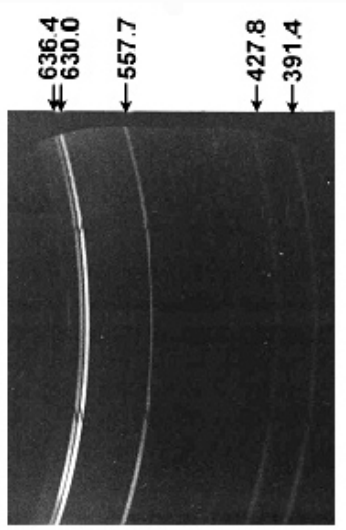

I $630.0>$ I 557.7

c

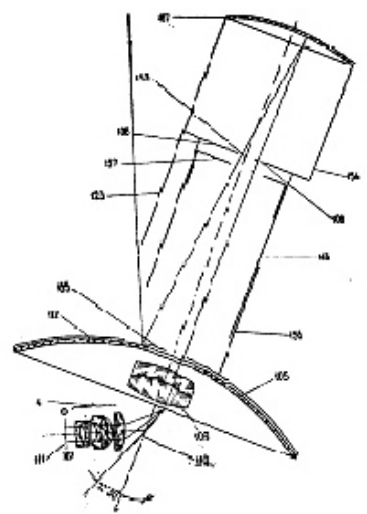

Optical diagram of C-180-S b

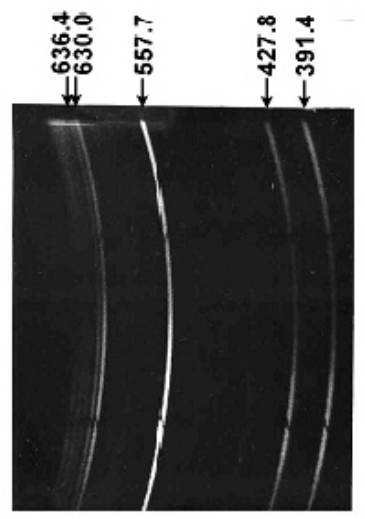

I $630.0<$ I 557.7 d
Fig. 5. Auroral spectral camera C-180-S (a, b) and typical auroral spectra obtained in Pyramida (c, d).

\section{Discussion and conclusion}

A number of auroras under our analysis can conventionally be considered as red type A aurora, during the periods of both high and low solar activity. This is coincident with the results of Yevlashin (1961, 2005); Sandholt et al. (2002), where features of the red and the green oxygen emission intensities in the cleft region were considered. In the present study, it is shown that the character of the auroral luminosity in the minimum of solar activity changes significantly compared to the period of high solar activity. The red type A aurora occurrence rate is negligible relative to the occurrence rate of the green aurora near the minimum of solar activity cycle while those occurrence rates are nearly equal near the maximum of solar activity (Fig. 6). The reason for such a big difference could be in the different parameters of the solar wind and (or) position and movement of the auroral oval polar boundaries (Stringer and Belon, 1967; Feldstein and Starkov, 1968; Vorobiev et al., 1984). The latter supposi-

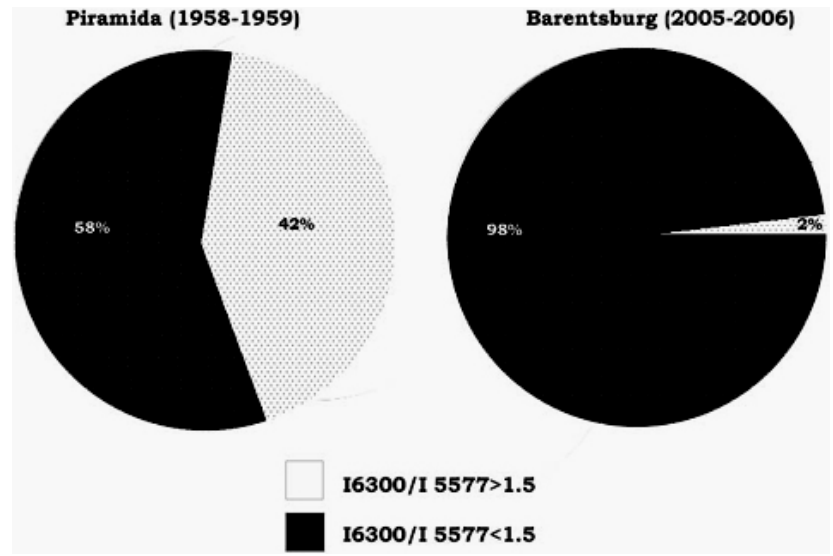

Fig. 6. Comparison of the relative distribution of auroral events with red or green oxygen auroral emissions.

tion, unfortunately, is not a part of the results of Yevlashin (2005), who showed that the average annual number of observations of type A red aurora completely corresponds to the solar activity variations in the 11-year cycle on the basis of Murmansk $\left(\Phi \sim 64.1^{\circ} \mathrm{N}, \Lambda \sim 126.5^{\circ} \mathrm{E}\right)$ spectral camera C$180-\mathrm{S}$ measurements. Therefore, we can suggest that the increase in the occurrence rate of the red type A aurora during solar maximum years is a common feature both in the polar cap and the auroral zone. This result requires a common source of soft particle fluxes responsible for the red emission excitation during both high and low solar activities. One of the candidates may be an increased value of the solar wind plasma density during high solar activity and auroral disturbances. Such a possibility is pointed out in Khviyuzova and Leontiev (2002); Vorobiev and Yagodkina (2006), where the appearance of the red auroral oxygen emission is related to the solar wind parameters. These results indicate that the solar wind plasma can rather effectively penetrate deep into the region of closed field lines in the dayside magnetosphere and into the Earth's nightside under special conditions. The exact mechanism remains to be identified.

The new S-180 camera measurements allow, for the first time, to compare the ratios of the red and green oxygen emission intensities in the polar cap during the high and low solar activity. This work will be continued to better understand the solar wind and magnetosphere contribution to the process of formation and excitation of the red type A aurora.

Acknowledgements. This research was partly supported by the Nordic Council of Ministers through grant 087043-60105, Network for Groundbased Optical Auroral Research in the Arctic Region, by the Norwegian Science Council grant number 178911 \S30 NORUSCA, by the Russian Fund of Basic Research grant number 0605-65044. Authors thank C. Deehr for his extremely useful comments.

Topical Editor U.-P. Hoppe thanks C. Deehr and another anonymous referee for their help in evaluating this paper. 


\section{References}

Chamberlain, J.: Physics of the auroras and airglow, New York and London Academic Press, p. 1-704, 1961.

Chernouss, S. A., Starkov, G. V., and Yevlashin, L. S.: World first complex optical instrumental observations of aurora in the Arctic in 1899-1900, Ann. Geophys., 23, 1523-1531, 2005, http://www.ann-geophys.net/23/1523/2005/.

Feldstein, Y. I. and Starkov, G. V.: Auroral oval in the IGY and IQSY period and a ring current in the magnetosphere, Planet. Space Sci., 17, 129-133, 1968.

Hanna, P. B. and Anger, C. D.: Auroral colour variations, Planet. Space Sci., 19(4), 399-411, 1971.

International Auroral Atlas: IUGG, Edinburgh University Press, 1963.

Khviyuzova, T. A. and Leontiev, S. V.: Effect of Solar-Wind Density on the Intensity of Red $(630.0 \mathrm{~nm})$ Auroral Emission, Geomagnetism and Aeronomy, 42(4), 519-521, 2002.

Koizumi, N., Okano, S., Sakanai, T., Tagushi, M., and Aso, T.: Auroral $\mathrm{O}^{+} 732 / 733 \mathrm{~nm}$ emission and its relation to ion upflow, Adv. Polar Upper Atmos. Res., 8, 96-104, 2004.

Lebedinsky, A. L.: Synchronous auroral registration by all-sky camera C-180 and patrol spectrograph C-180-S, Ann. Int. Geophys. Year, 11, 133-144, 1961.

Rees, M.: Physics and chemistry of the Upper Atmosphere, Cambridge University Press, p. 1-266, 1989.

Roldugin, A. V., Sharovarova, O. M., Pilgaev, S. V., Fedorenko, Yu. V.: Meridian All-Sky Imaging Spectrograph in Barentsburg, Spitsbergen in Coming 2006-2007 Observational Season, The 3d International Conference Geophysical Research in Spitsbergen Archipelago, 3-5 October 2006, Extended abstracts, Publ. of the Polar Geophysical Institute and Kola Science Centre RAS, 5458, 2006.
Sandford, B. P.: Aurora and airglow from color film observations, J. Atmos. Terr. Phys., 21(2/3), 177-181, 1961.

Sandholt, P. E., Moen, J., Budland, A., Opsvik, D., Denig, W. F., and Hansen, T.: Auroral event sequences at the dayside polar cap boundary for positive and negative interplanetary magnetic field By, J. Geophys. Res., 98(5), 7737-7755, 1993.

Sandholt, P. E., Carlson, H. C., and Egeland, A.: Dayside and Polar Cap Aurora, Cluver Academic Publishers, p. 1-287, 2002.

Stringer, W. J. and Belon, A. E.: The statistical auroral zone during IQSY and its relationship to magnetic activity, J. Geophys. Res., 72(1), 245-250, 1967.

Vallance Jones, A.: Aurora, D. Reidel Publishing Company, p. 1301, 1974.

Vorobiev, V. G., Tagirov, V. R., and Chernouss, S. A.: Relative Position of the Zones of Soft Precipitations and Auroral Pulsations in the Daytime Polar Region, Geomagnetism and Aeronomy, 24(2), 284-286, 1984.

Vorobiev, V. G. and Yagodkina, O. I.: Influence of the Solar Wind Plasma Density on the Auroral Precipitation Characteristics, Geomagnetism and Aeronomy, 46(1), 52-57, 2006.

Yevlashin, L. S.: Red Type A Auroras in High Latitudes, Geomagnetism and Aeronomy, 1(4), 531-533, 1961.

Yevlashin, L. S.: Aperiodic Variations in the Occurrence Frequency of Red Type-A Auroras during the 11-Year Cycle of Solar Activity, Geomagnetism and Aeronomy, 45(3), 388-391, 2005. 